\title{
Altered adipose tissue and adipocyte function in the pathogenesis of metabolic syndrome
}

\author{
C. Ronald Kahn, ${ }^{1}$ Guoxiao Wang, ${ }^{1}$ and Kevin Y. Lee ${ }^{2,3}$ \\ 'Section on Integrative Physiology and Metabolism, Joslin Diabetes Center, Harvard Medical School, Boston, Massachusetts, USA. Department of Biomedical Sciences, Heritage College of Osteopathic \\ Medicine, and ${ }^{3}$ The Diabetes Institute, Ohio University, Athens, Ohio, USA.
}

\begin{abstract}
Over the past decade, great progress has been made in understanding the complexity of adipose tissue biology and its role in metabolism. This includes new insights into the multiple layers of adipose tissue heterogeneity, not only differences between white and brown adipocytes, but also differences in white adipose tissue at the depot level and even heterogeneity of white adipocytes within a single depot. These inter- and intra-depot differences in adipocytes are developmentally programmed and contribute to the wide range of effects observed in disorders with fat excess (overweight/obesity) or fat loss (lipodystrophy). Recent studies also highlight the underappreciated dynamic nature of adipose tissue, including potential to undergo rapid turnover and dedifferentiation and as a source of stem cells. Finally, we explore the rapidly expanding field of adipose tissue as an endocrine organ, and how adipose tissue communicates with other tissues to regulate systemic metabolism both centrally and peripherally through secretion of adipocyte-derived peptide hormones, inflammatory mediators, signaling lipids, and miRNAs packaged in exosomes. Together these attributes and complexities create a robust, multidimensional signaling network that is central to metabolic homeostasis.
\end{abstract}

Obesity, i.e., increased adipose tissue mass, is a major driving force in insulin resistance and the pathogenesis of type 2 diabetes (T2D) and metabolic syndrome. Over the past decade it has become clear that this association depends not only on the balance between energy intake and utilization, but also on the balance between white fat, which is the primary site of energy storage, and brown and beige adipose tissue, which are sites for energy expenditure $(1,2)$. On the other hand, lipodystrophy, i.e., complete or partial loss of body fat, can also be associated with insulin resistance and metabolic syndrome (3). These diametrically opposed states illustrate the complex interaction between body fat and the control of metabolism. In addition, some people appear metabolically healthy despite obesity, and there is growing evidence that this may reflect the fact that white adipose tissue is heterogeneous and that different classes of adipocytes have differing metabolism and ability to communicate with other tissues by secretion of peptides, lipids, and miRNAs, which affect systemic metabolism differently (4-6). In this Review, we will explore these relationships, focusing on some of the newest aspects linking adipose tissue to the control of whole-body metabolism.

\section{Heterogeneity of adipose tissue at multiple levels}

Adipose tissue is classically divided based on anatomic location and major cell type constituent (Figure 1A). Histologically, there are three major types of adipose tissue: white adipose tissue (WAT), which represents more than $95 \%$ of adipose mass; brown

Conflict of interest: The authors have declared that no conflict of interest exists. Copyright: (c) 2019, American Society for Clinical Investigation. Reference information: J Clin Invest. 2019;129(10):3990-4000. https://doi.org/10.1172/JCI129187. adipose tissue (BAT), which represents $1 \%$ to $2 \%$ of fat and, in humans, occurs in small collections in the cervical, axillary, and paraspinal regions; and beige/brite adipose tissue, which is difficult to quantitate but represents cells interspersed within WAT that are capable of transforming into brown-like adipocytes following cold exposure or adrenergic stimulation. In contrast to white adipocytes, which have a large unilocular lipid droplet, brown and beige adipocytes have multilocular droplets and high mitochondrial density for dissipation of energy through uncoupled mitochondrial respiration, a feature that could potentially be used to combat obesity $(1,2)$. In vivo, the abundance of BAT and, to some extent, beige fat can be estimated using PET/CT with 2-deoxy-2-[18 F]fluoroglucose $(1,2)$, xenon-enhanced CT (7), and, in mice, luciferase-based markers (8); however, these techniques all depend on functional aspects of brown and beige fat and do not necessarily represent the actual mass of tissue.

In addition, it is important to keep in mind that adipocytes only make up a portion of the adipose depot and that adipose tissue contains other cell types that contribute to its physiology and pathophysiology, including preadipocytes, mesenchymal stem cells, vascular cells, and inflammatory cells. While there is no specific marker for preadipocytes, studies suggest that these may come from vascular mural cells, pericytes, and/or adventitial fibroblasts and include adipogenic and fibrogenic subtypes (9-11). Fat also contains dipeptidyl peptidase-4-expressing $\left(\mathrm{DPP} 4^{+}\right)$multipotent progenitors that give rise to committed preadipocytes and $\mathrm{CD} 142^{+}$cells, which have anti-adipogenic properties (12). In addition, a fibroblast population that secretes fibroblast-specific protein- 1 (FSP1+ fibroblasts) is important for maintaining the preadipocyte pool (13).

Depot-specific differences between visceral and subcutaneous adipose tissue. Anatomically, WAT is divided into visceral and subcutaneous depots. Accumulation of visceral intra-abdominal 
A

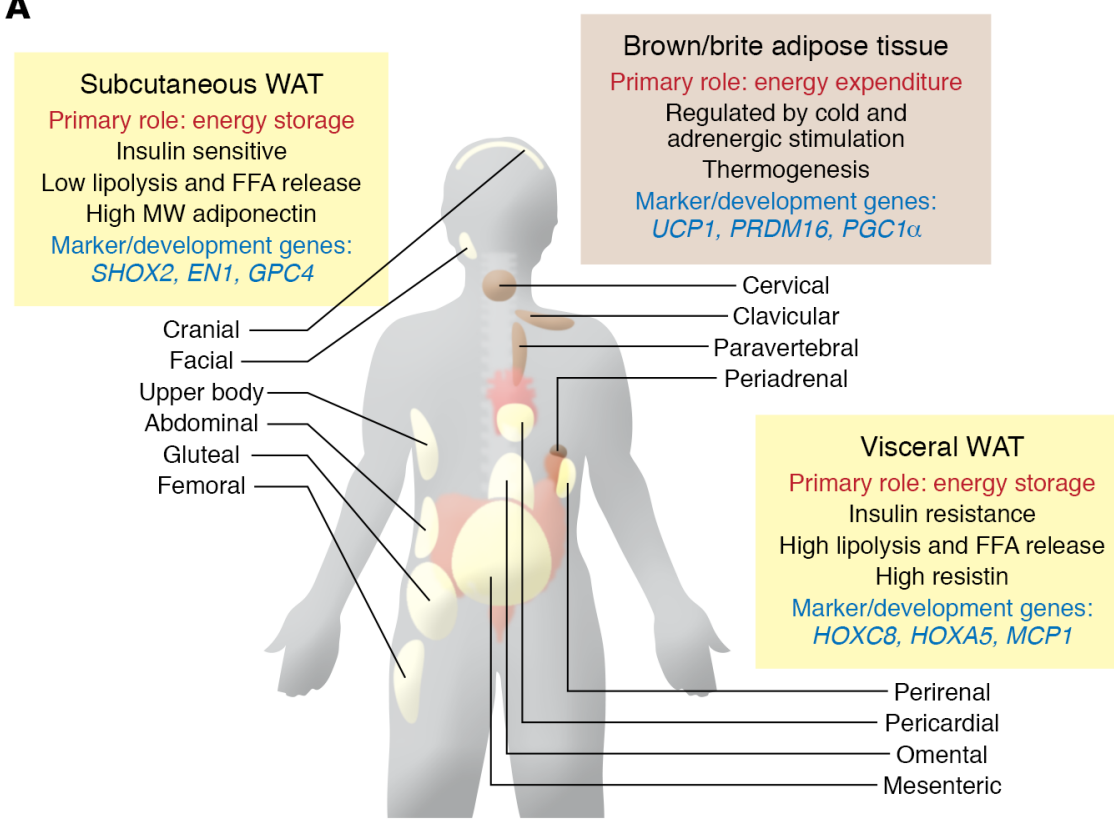

B

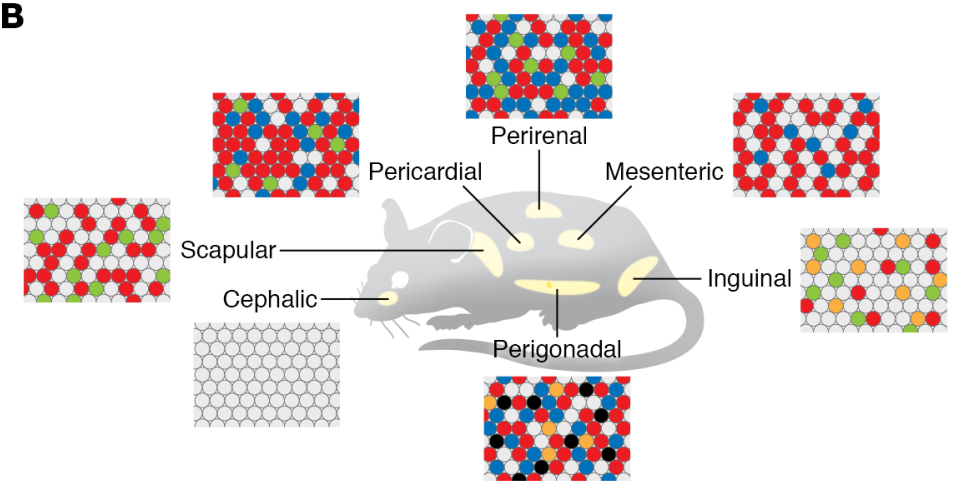

Adipocyte developmental origin

- Type 1: mesothelial (Wt1)

- Type 2: vascular smooth muscle (Tagln, SMA)

- Type 3: immune-related (Mx1)

- Type 4: hematopoietic? (bone marrow)

Type 5: vascular endothelium? (VE-cadherin)

Type 6, 7, other

Figure 1. Heterogeneity of adipose tissue at multiple levels. (A) Human adipose tissue illustrating the multiple depots of brown and white subcutaneous and visceral fat. The different roles, properties, and marker/development genes of these depots are indicated. (B) Heterogeneity of adipose tissue in the mouse, showing different depots of white adipose tissue, each containing a mixture of white adipocytes of different subtypes.

ipocytes have higher expression of short stature homeobox 2 (Shox2) and glypican-4 (GPC4), which repress lipolysis and insulin sensitivity, respectively (24-27), whereas visceral adipose tissue has higher levels of HoxC 8 and HoxA5, which regulate browning and adipogenesis $(28,29)$.

In addition to subcutaneous and visceral fat, WAT in other depots may have distinct functions and effects on metabolism. White adipocytes within dermal layers are developmentally distinct from subcutaneous WAT (30) and play roles in wound healing, hair development, and pathogen resistance (31). Bone marrow adipose tissue (MAT) is also a distinct depot and includes two distinct subtypes (32): constitutive MAT (cMAT), concentrated in the distal skeletal bones, and regulated MAT (rMAT), which is diffusely distributed in the spine and proximal limb bones and is regulated in response to environmental factors $(33,34)$. MAT plays important roles in bone metabolism and osteoblastic activity (35). Interestingly, MAT is not depleted in calorically deficient states and may be a major source of circulating adiponectin $(36,37)$.

Intra-depot heterogeneity in adipose tissue. A growing body of evidence indicates that adipocytes, even within a single fat pad, are heterogeneous in nature both genetically and metabolically (Figure 1B and refs. 38-41).

WAT, i.e., central obesity, is associated with insulin resistance and increased risk of metabolic disease, whereas accumulation of subcutaneous WAT, i.e., fat in the hips and flanks, has no adverse effect and may even be protective against metabolic syndrome $(14,15)$. Indeed, studies have shown lower cardiovascular risk in individuals with subcutaneous obesity, independent of whether they have visceral obesity $(16,17)$. In rodents, transplantation of subcutaneous WAT improves glucose metabolism, indicating that these depot effects are mediated, at least in part, by cell-autonomous differences, not simply anatomical position $(18,19)$. Consistent with this, subcutaneous preadipocytes have increased rates of proliferation and lipid accumulation $(20,21)$, whereas visceral adipocytes have increased rates of lipolysis and increased susceptibility to apoptosis $(22,23)$. Many of these differences are due to variations in gene expression, including the expression of developmental genes $(21,24-26)$. Thus, subcutaneous adipocytes/pread-
This was initially suggested by a bimodal size distribution of adipocytes in mice with fat-specific ablation of the insulin receptor or hormone-sensitive lipase (HSL) $(42,43)$. Recent studies using clonal cell analysis and single-cell RNA-Seq further highlight this heterogeneity. Thus, white preadipocytes with low levels of CD9 are more adipogenic, whereas preadipocytes with high CD9 are more profibrotic and proinflammatory (44). By combining clonal analysis and lineage tracing, Lee et al. identified at least three functionally and developmentally distinct subpopulations of white preadipocytes in mice characterized by unique gene expression profiles and high expression of the marker genes Wilms tumor-1 (Wt1), transgelin, and myxovirus-1 (Mx1), termed types 1-3, respectively (45). Likewise, single-cell transcriptomic profiling of human preadipocytes and mesenchymal progenitor cells (46) has identified up to four adipocyte subtypes, including a beige/brite thermogenic subtype and a subtype specialized for leptin secretion. 

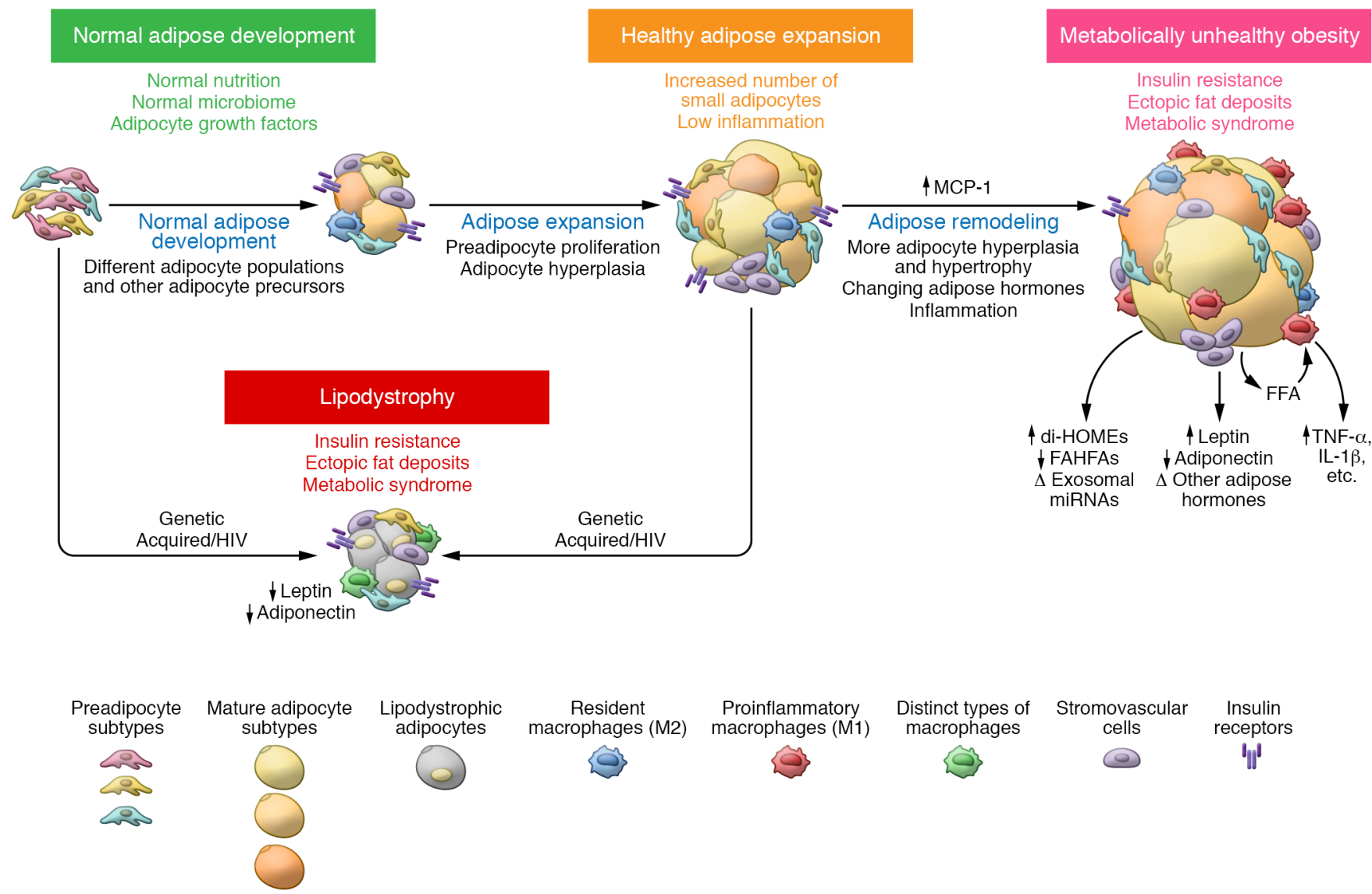

Figure 2. Adipose tissue development and remodeling in health and disease. From left to right, the figure illustrates the conversion of preadipocytes to mature adipocytes followed by adipose expansion due to preadipocyte proliferation and hyperplasia of adipocytes followed by adipocyte hypertrophy, adipose tissue inflammation, and changes in adipocyte hormone leading to insulin resistance. In lipodystrophy this process is also disrupted, leading to insulin resistance.

Lineage tracing has also provided insights into different developmental origins of white adipocytes. Using a tetracycline transactivator under the control of the PPAR $\gamma$ gene locus, Tang et al. demonstrated that preadipocytes can be found within the mural cell compartment of the adipose vasculature (9). A subset of these preadipocytes, marked by smooth muscle actin (SMA), was found to be important in adipose tissue homeostasis later in life (47). Transgelin (also called smooth muscle-22 $\alpha$ ) is also highly expressed in vascular smooth muscle and pericytes, suggestive of similar mural origin, and marks a subset of adipocytes in all depots (45, 48). Some adipose progenitor cells can be labeled by endothelialspecific VE-cadherin-Cre, and the preadipocyte marker Zfp423 is found in both mural and vascular endothelial precursors, further supporting the idea of a vascular origin of preadipocytes (49).

The visceral mesothelium, which covers internal organs, has been shown to contribute to adipocyte lineages in visceral and cardiac adipose depots. This subpopulation of adipocytes has reduced triglyceride accumulation and highly glycolytic metabolism (45). Mesothelial cells are highly responsive to inflammatory signals and secrete high levels of IL- 6 and IL-8 following stimulation $(50,51)$, suggesting a potential role for mesothelial-derived adipocytes in the inflammatory response in visceral fat.

Most adipose originates from the mesoderm. Lineage tracing using the paraxial mesoderm-specific genes Meox1, Pax3/7, and
$M y f 5$, originally thought to give rise only to brown adipocytes and skeletal muscle, also gives rise to subsets of white adipocytes in retroperitoneal and interscapular depots $(52,53)$. By contrast, lateral plate mesoderm, marked by HoxB6, contributes to posterior and ventral adipose depots, including inguinal, mesenteric, and perigonadal WAT of mice (Figure 2B). Lineage tracing has shown that Prx1-expressing progenitors gives rise to a majority of subcutaneous, but not visceral, adipocytes $(54,55)$. A subset of visceral white adipocytes may be bone marrow-derived from hematopoietic lineages (56), although this has been challenged (10). Finally, a subset of adipocytes in the face and neck are derived from neural crest progenitors marked by Wnt1 and Sox10 $(57,58)$, although over time they are replaced by mesodermalderived adipocytes (59).

Brown and beige adipocytes also display intrinsic heterogeneity and a broad range of thermogenic competency (60-62). Similarly, beige adipocytes demonstrate distinct subpopulations with differences in the expression of regulators of lipid synthesis and oxidation (63). Beige/brite adipocytes may also be derived from different developmental sources, including a vascular smooth muscle origin (64). Lastly, a developmentally distinct type of glycolytic beige fat has been described (65). Molecular characterizations of BAT in adult humans suggest that it may be composed of both conventional brown fat cells and beige/brite adipocytes $(61,62)$. 


\section{Lipodystrophy - clinical evidence of adipocyte heterogeneity}

Lipodystrophies encompass a range of genetic and acquired disorders in which the body is unable to produce/maintain adipose tissue, resulting in either partial or generalized loss of fat (66). The effects of absence of adipose tissue on metabolism are strikingly similar to those found in individuals with an excess of adipose tissue, i.e., severe insulin resistance, hypertriglyceridemia, hepatic steatosis, and metabolic syndrome $(3,67)$, indicating the critical role of maintaining an optimal adipose tissue mass in the regulation of metabolism. One common feature of obesity and lipodystrophy is the diversion of excess calories into formation of ectopic fat in other tissues, including liver, skeletal muscle, and pancreatic $\beta$ cells. This ectopic fat deposition is thought to directly drive insulin resistance $(68,69)$. The concept that adipose tissue provides protection against ectopic storage is supported by mouse models overexpressing adiponectin or with knockout of collagen VI, both of which allow for uninhibited expansion of adipose tissue and improved glucose and insulin sensitivity $(70,71)$. This is also observed in mouse models with genetic or pharmacological inhibition of lipolysis and $\beta$-oxidation $(72,73)$. In addition to lipid storage, the low levels of adiponectin and leptin in patients with lipodystrophy may play important roles in mediating the severe insulin resistance and metabolic complications. Leptin infusion into lipodystrophic patients or mice improves insulin sensitivity and decreases hepatic and circulating triglycerides $(74,75)$.

The abnormal distributions of adipose tissue seen in partial lipodystrophies support the concept of developmental and functional heterogeneity of adipose tissue. Dunnigan-type familial partial lipodystrophy is characterized by the loss of subcutaneous fat in the extremities and trunk, but an accrual of fat in the visceral and head/neck regions $(76,77)$. Similarly, patients with mutations in the p85 $\alpha$ regulatory subunit of PI3K, which is critical for adipocyte differentiation, are characterized by selective lipoatrophy of subcutaneous and facial fat (78), and patients with Barraquer-Simons syndrome have selective loss of upper body fat (79). Although many of the genes implicated in various forms of partial lipodystrophy, including those encoding PPAR $\gamma$, CIDEC, perilipin-1, and AKT-2, are known to have critical roles in adipocyte biology, why these lead to loss (or gain) of fat in particular regions remains unknown (80-82). Finally, an acquired form of lipoatrophy associated with increased dorsocervical adipose tissue (buffalo hump) is observed in treated HIV patients and has been attributed to changes in transcription factors and miRNAs involved in differentiation and increased adipocyte apoptosis $(83,84)$.

\section{Adipose tissue turnover}

In terms of mass, WAT is the most variable and dynamic tissue in the body, ranging from less than $2 \%$ to more than $70 \%$ of body weight. The dramatic increase in fat mass in obesity can occur through adipocyte hypertrophy, i.e., enlargement due to lipid accumulation, and adipocyte hyperplasia, i.e., proliferation/differentiation of preadipocytes resulting in increased numbers of adipocytes (Figure 2 and ref. 14). In general, the total number of fat cells is set during childhood and remains constant through adulthood $(85,86)$, but may be increased with early-onset obesity and in some depots in adults by overfeeding (87).
Taking advantage of changes in atmospheric ${ }^{14} \mathrm{C}$, Spalding et al. have shown that in humans approximately $10 \%$ of adipocytes are replaced every year, regardless of age or obesity, whereas the half-life of adipocyte triglycerides is only approximately 1.6 years (86). Individuals with hypertrophic obesity tend to produce fewer adipocytes than individuals with hyperplastic obesity (88). While heavy water labeling suggests that adipocyte and triglyceride turnover may be higher (89), studies using multi-isotope imaging mass spectrometry find similar results to the atmospheric ${ }^{14} \mathrm{C}$ studies (90). Likewise, basal adipocyte turnover is very low in rodents, but can be accelerated by high-fat diet (HFD) feeding (91). The effect is depot-specific and higher in visceral versus subcutaneous fat (92). Lineage tracing studies show that adipogenesis increases in visceral fat within 4 weeks of HFD feeding (93). The full capacity for adipose tissue regeneration is observed in models in which adipose tissue is acutely ablated, such as the Fat-AATC mouse (in which apoptosis in adipose tissue is induced by activation of caspase-8) (94) and mice with fat-specific inducible knockout of the insulin receptor and IGF-1R (95). Both lead to rapid fat loss followed by rapid induction of preadipocyte proliferation and differentiation, producing new populations of brown and white adipocytes to restore fat tissues and resolve the metabolic syndrome within 10-30 days. These results suggest the presence of a feedback mechanism that attempts to maintain adipose tissue mass.

Adipocyte dedifferentiation. Recent work suggests that adipocytes can also dedifferentiate back into pluripotent progenitor cells in vivo in both healthy and pathological conditions (96, 97). Lineage tracing has demonstrated that "pink" adipocytes in mouse mammary gland can give rise to mammary epithelial cells during lactation, then revert back to adipocytes during involution (98), although these reports have been challenged by others who find that it is adipocyte progenitors that transition into epithelial cells (99). Adipocyte dedifferentiation has also been linked to some cancers, including breast cancer (100), suggesting the therapeutic potential of PPAR $\gamma$ agonist treatment to revert some breast cancer cells into adipocytes. Dedifferentiated white adipocytes may also represent a source of stem cells to repair cardiac tissue and spinal cord injuries $(101,102)$. Adipocytes in dermal WAT can revert into myofibroblasts and contribute to wound healing (31).

\section{Adipose tissue as an endocrine organ}

Adipocyte hormones. Over the past two decades it has become clear that in addition to their roles in energy storage, adipose tissues are endocrine organs secreting a large number of factors with hormonal, autocrine, and paracrine properties (Figure 3 ). While a complete review of these adipocyte hormones is beyond the scope of this Review, many of them have important effects on metabolism.

Leptin is a $16-\mathrm{kDa}$ protein produced primarily by white adipocytes that acts on leptin receptors (LEPR/LepR) in the hypothalamus to suppress feeding and increase energy expenditure $(103,104)$. While LEPR has multiple isoforms, leptin's metabolic actions are mediated by the long-form LepRb, whose cytoplasmic tail associates with the Jak2 tyrosine kinase to mediate intracellular signaling. This engages multiple downstream molecules, including SHP-2 and STAT3, which regulate ERK activation and suppressor of cytokine signaling 3 (SOCS3) as well as PI3K (105). Mice and humans with mutations in leptin or LEPR are massively 


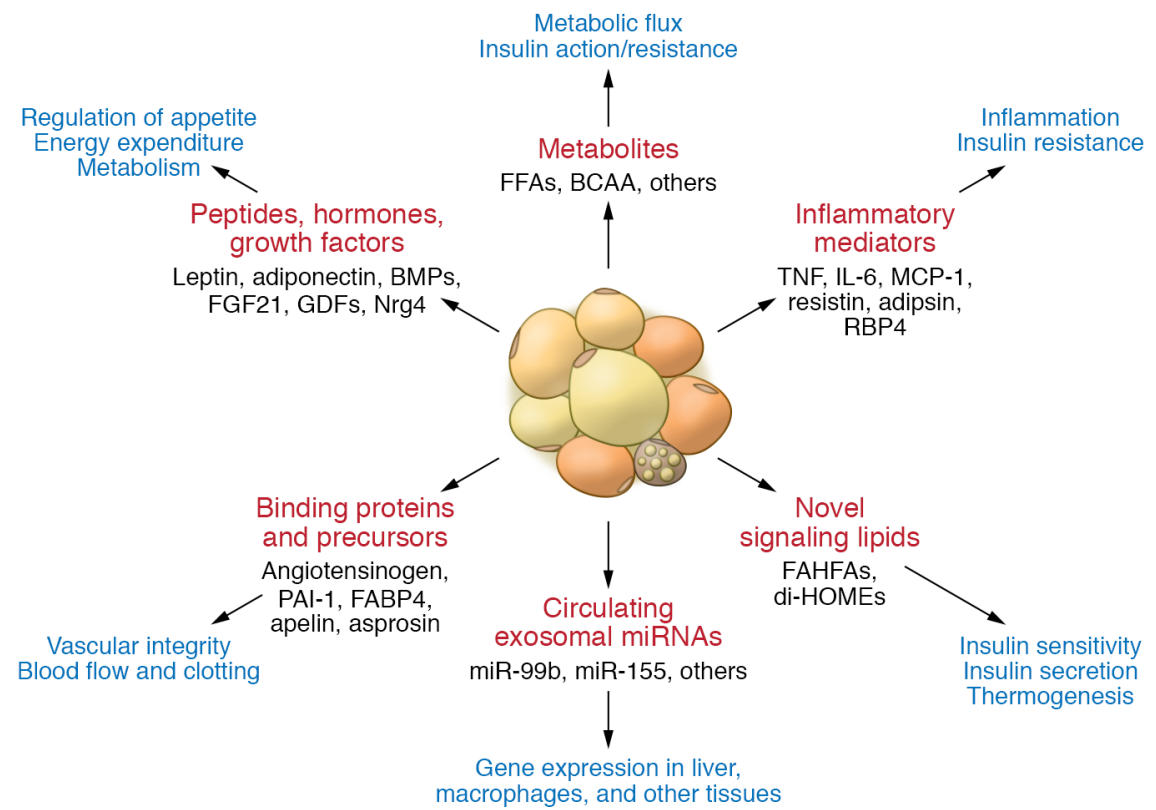

Figure 3. Adipocyte hormones in intertissue communication. The figure illustrates different classes of adipocyte hormones and their varied effects on metabolism and the development of insulin sensitivity or resistance. BCAA, branchedchain amino acids; GDF, growth differentiation factor ; Nrg4, neuroregulin 4. obese and hyperphagic (106-108). In humans or mice with obesity due to mutations in the leptin gene, treatment with recombinant leptin restores near-normal health. Unfortunately, common forms of human obesity do not respond to leptin, indicating leptin resistance $(108,109)$. Physiologically, leptin may be most important when its levels are low. In fasting or starvation, low leptin creates a strong stimulus for increased food intake and decreased energy expenditure $(110,111)$, and leptin replacement during fasting prevents starvation-induced changes in the hypothalamic-pituitary axis through actions on expression of corticotropin-releasing hormone, thyrotropin-releasing hormone, and gonadotropinreleasing hormone $(112,113)$. Some peripheral tissues also express LEPRs, contributing to leptin effects on bone, immune cells, and angiogenesis. Leptin treatment lowers blood glucose in mouse models of insulin-deficient diabetes, suggesting possible use in type 1 diabetes; however, this has not been shown in humans (114).

Adiponectin is an approximately $30-\mathrm{kDa}$ protein produced in both white and brown adipocytes, with the highest levels in subcutaneous WAT. Paradoxically, adiponectin levels are high when fat mass is low and vice versa. Adiponectin circulates as a range of multimers, from trimers to high-molecular weight (HMW) dodecamers $(115,116)$. HMW adiponectin appears to account for most of its effects (117). Adiponectin levels are markedly elevated in patients with severe insulin resistance due to anti-insulin receptor antibodies or insulin receptor mutations, suggesting feedback between insulin resistance and adiponectin secretion (118). Adiponectin acts to improve insulin sensitivity through two atypical seven-transmembrane receptors. In muscle, adiponectin acts through AdipoR1 to activate AMPK; in liver, adiponectin acts on both AdipoR1 and AdipoR2 to suppress hepatic glucose output $(119,120)$. Whether the latter effect occurs through AMPK or increased ceramidase activity is controversial $(121,122)$. In addition, adiponectin can act in the CNS to stimulate appetite, reduce energy expenditure, and perhaps affect neurodegeneration (123, $124)$; on endothelial cells, it affects angiogenesis $(125,126)$.
In addition to leptin and adiponectin, adipose tissue produces a number of other peptide adipocyte hormones linked to insulin resistance and metabolic syndrome. Resistin is an approximately $12-\mathrm{kDa}$ polypeptide. In mice, resistin is produced mainly by visceral WAT and was shown to induce insulin resistance through a mechanism involving SOCS3 activation $(127,128)$. In humans, resistin is produced mainly by macrophages, and its role in insulin resistance is less clear (129). Retinol-binding protein 4 (RBP4) is also produced by visceral adipocytes and other tissues, especially liver $(130,131)$. RBP4 can activate promote adipose tissue inflammation, thus contributing to insulin resistance $(130,132)$. Other peptide adipocyte hormones include apelin, which has three active peptides potentially involved in regulating cardiovascular function $(133,134)$; omentin, an insulin-sensitizing peptide produced by non-adipocyte cells in adipose depots (135); vaspin, a serine protease inhibitor thought to act as an insulin sensitizer (135); nesfatin-1, a peptide derived from nucleobinding-2 suggested to potentiate glucose-induced insulin secretion from $\beta$ cells (136); DPP4, the peptidase that degrades GLP-1 (137); and asprosin, a cleavage product of the fibrillin- 1 gene, which stimulates hepatic glucose release (138).

Adipose tissue is also a source of multiple growth factors, including FGF21, BMPs, TGF- $\beta$, VEGFs, and growth differentiation factors. BMPs such as BMP2, BMP4, BMP7, and BMP8b not only come from fat but also play important roles in fat. BMP2 and BMP4 stimulate white adipocyte differentiation $(139,140)$, whereas BMP7 is critical for brown adipocyte development (141). BMP4 also plays a role in development and browning of WAT, while BMP8b enhances BAT's response to $\beta_{3}$-adrenergic stimulation (142). VEGF-A, a potent angiogenic factor, is expressed in both white and brown adipocytes (143) and is important in sustaining adequate circulation to adipose tissue $(144,145)$. Finally, adipose tissue is a site for production of neurotrophic factors such as NGF, Nrg4, and the semaphorins, which play a particularly important role in innervation of BAT. 


\section{Adipose tissue and inflammatory crosstalk in insulin resistance}

Inflammation in adipose tissue is a characteristic of obesity and is marked by secretion of multiple inflammatory cytokines and proteins of the alternate complement system, as well as infiltration of adipose tissue with macrophages and leukocytes. Evidence for a role of inflammation as a component of T2D dates to the century-old observation that high doses of sodium salicylate reduce blood glucose in people with T2D (146). This occurs through inhibition of the IKK $\beta / N F-\kappa B$ pathway and improvement in insulin sensitivity (147, 148). Epidemiologically, T2D is associated with increased levels of markers/mediators of inflammation, including C-reactive protein, IL-6, plasminogen activator inhibitor-1 (PAI-1), and TNF- $\alpha$ (reviewed in ref. 149). TNF- $\alpha$ expression is increased in adipose tissue in rodent models of obesity and diabetes (150), where it induces insulin resistance by impairing insulin receptor and insulin receptor substrate-1 (IRS-1) phosphorylation (151). Neutralizing TNF- $\alpha$ increases peripheral tissue glucose uptake in obese diabetic rats (150). Although one clinical trial showed that targeting TNF- $\alpha$ can reduce hyperglycemia in patients with metabolic syndrome (152), most studies report no beneficial effect of TNF- $\alpha$ antagonism on insulin sensitivity (153, 154), questioning TNF- $\alpha$ 's role as the causative link between adipose tissue inflammation and insulin resistance in humans.

In obesity, adipose tissue undergoes remodeling during which macrophages infiltrate the tissue and secrete multiple proinflammatory cytokines. Increased expression of monocyte chemoattractant protein-1 (MCP-1) is seen as early as 3 weeks after HFD feeding in rodents; however, the number of macrophages in WAT does not increase until 10 to 16 weeks later (155), suggesting that adipose tissue inflammation could be an adaptive response to insulin resistance rather than its cause. Indeed, immunocompromised mice develop a degree of insulin resistance similar to that in controls after short-term HFD feeding (156). Supporting the idea that proinflammatory signaling in adipocytes may be required for healthy expansion of visceral WAT, an impaired proinflammatory response in adipocytes can lead to ectopic lipid accumulation and glucose intolerance in mice on HFD (157). It has also been suggested that an ineffective inflammatory response in mesenteric WAT could allow gut microbial-derived antigens to enter the circulation and serve as triggers for systemic inflammation (157).

In addition to increased macrophage number, the polarity of adipose tissue macrophages also changes during obesity progression (158). In obesity, there is an increase in M1 (classically activated) macrophages, while alternatively activated M2 macrophages are reduced. This change is thought to occur through proinflammatory mediators, such as lipopolysaccharide. $\mathrm{T}$ cells have also been found in adipose tissue, and their composition changes as obesity progresses, with increased infiltration of $\mathrm{CD} 8^{+}$cytotoxic $\mathrm{T}$ cells and decreased presence of regulatory $\mathrm{T}$ cells $(159,160)$. These changes precede macrophage infiltration. Drugs that block the effects of proinflammatory cytokines, such as CCL2 antagonists and IL-1R antagonists, reduce systemic inflammation and improve glycemic control in obese/diabetic rodents (161). Amlexanox, an inhibitor of noncanonical IKB kinases IKK $\varepsilon$ and TBK1, also shows beneficial effects in both rodents and humans $(162,163)$.

Emerging evidence suggests that adipose tissue fibrosis also plays a role in the regulation of adipose tissue health (see ref. 164, this issue of the JCI). Clinical studies report a link between excess extracellular matrix accumulation in subcutaneous WAT and insulin resistance (165). Importantly, repression of adipose tissue fibrosis by whole-body collagen VI knockout (71) or adipose tissuespecific repression of profibrosis program (166) significantly improves glucose metabolism, suggesting that adipose tissue fibrosis is more than just a morphological marker of dysfunctional fat.

\section{Signaling lipids as adipocyte hormones}

The normal physiology of lipid storage as triglycerides and release as free fatty acids (FFA) and glycerol means that adipose tissue is a site of high lipid flux. In addition, adipose tissue may secrete specialized signaling lipid species that mediate communication between adipose tissues and other tissues.

One class are the branched fatty acid esters of hydroxyl fatty acids called branched fatty acid esters of hydroxy fatty acids (FAHFAs) (167). These were discovered to be markedly elevated in mice with Glut4 overexpression in adipose tissue and were associated with the improved metabolic phenotype in these mice (167). FAHFAs may have varying fatty acid composition, including palmitoleic acid, palmitic acid, or oleic acid as the fatty acid moiety, and hydroxyl-palmitic acid or hydroxyl-steric acid as the hydroxylfatty acid moiety, creating many isoforms. The effects of palmitic acid-hydroxy-stearic acids (PAHSAs) have been studied in the most detail. Serum PAHSA levels are decreased in insulin-resistant humans and positively correlate with insulin sensitivity (167). Oral gavage of 5-PAHSA and 9-PAHSA reduces blood glucose levels in HFD-fed mice and improves glucose tolerance in both chow- and HFD-fed mice (167). Chronic PAHSA administration in HFD-fed mice improves insulin sensitivity and glucose tolerance (168). Mechanistically, PAHSAs exert their beneficial effects through activating GPR12O and GPR40 $(167,168)$. Knockdown or blockade of GPR120 reverses the enhanced insulin-stimulated glucose transport in PAHSA-treated adipocytes (167). Blocking GPR40 inhibits PAHSA augmentation of glucose-stimulated insulin secretion from islets $(167,168)$. Less abundant fatty acids, such as docosahexaenoic acid (DHA), can also be incorporated into novel FAHFAs if provided externally (169). Both human and murine WAT can synthesize several kinds of DHA hydroxyl-linoleic acid (DHAHLA). 13-DHAHLA demonstrates antiinflammatory properties and reduces LPSinduced macrophage activation (169). Although enzymes responsible for FAHFA synthesis have not been identified, four FAHFAspecific hydrolases, AIG1, ADTRP, CEL, and Ces3/CES1, have been identified $(170,171)$. These inhibitors could serve as a new class of antidiabetic and antiinflammatory drugs.

A second class of lipid adipocyte hormones are the diHOMEs, products of linoleic acid metabolism, such as 12,13-dihydroxy-9Zoctadecenoic acid (12,13-diHOME). Lynes et al. have shown that 12,13-diHOME is elevated in BAT versus WAT, and its levels in BAT and serum increase upon cold exposure in humans and rodents (172). 12,13-diHOME then acts back on BAT to increase fatty acid uptake, resulting in enhanced cold tolerance (172). Increased release of 12,13-diHOME in BAT has also been observed following exercise, and its actions on skeletal muscle increase fatty acid uptake and oxidation (173). Recently, 12,13-diHOME was also identified in peripheral nervous tissues in response to inflammatory pain (174). Thus, induction of 12,13-diHOME in BAT might be part of a stress response. 


\section{Exosomal miRNAs as novel adipocyte "hormones"}

miRNAs are small noncoding RNAs of approximately $22 \mathrm{nt}$ produced by all cells of the body (175). miRNAs play important roles in differentiation and function of brown, beige, and white fat (83, $176,177)$. In addition, miRNA expression in adipose tissue differs between obese and lean humans $(178,179)$, and levels of these miRNAs variably correlate with BMI, glycemia, and insulin resistance. The importance of miRNAs in adipose development/function is illustrated by the fact that adipocyte-specific knockout of the miRNA-processing enzyme DICER (ADicerKO) or its partner DGCR8 (ADgcr8KO) in mice produces partial lipodystrophy and insulin resistance $(83,180,181)$.

There is growing evidence that fat is a major source of circulating miRNAs and that miRNAs secreted by adipocytes, especially those in extracellular vesicles or exosomes, may participate in intertissue communication and serve as novel adipose hormones. Thus, ADicerKO mice exhibit significant decreases in about half of circulating exosomal miRNAs (6). Circulating exosomal miRNAs are also decreased in humans with genetic or HIV-related lipodystrophy, and in the latter this is associated with a decrease in DICER in adipose tissue $(6,84)$. These adipose-derived circulating miRNAs can act on other tissues like liver and muscle to modulate mRNA translation and stability $(6,182)$. An example of an adipose-derived circulating miRNA contributing to the control of metabolic homeostasis is the regulation of liver FGF21 by adipose-derived miR-99b (6). Accordingly, ADicerKO mice have reduced levels of miR-99b in circulating exosomes and upregulation of Fgf21 mRNA and its 3'-UTR reporter activity in liver (6), which can be partially corrected by administration of exosomes loaded with miR-99b. ADicerKO mice exhibit a wide range of phenotypes reflecting dysfunction in other nonadipose tissues, as well as systemic insulin resistance $(83,181)$, suggesting that this is a generalized mechanism of intertissue communication.

Since adipose tissue is a major contributor to circulating exosomal miRNAs, it is not surprising that circulating miRNAs are altered in individuals with obesity, lipodystrophy, T2D, and metabolic syndrome, and may contribute to insulin resistance in these diseases $(6,183-187)$. In obese humans and rodents, there is upregulation of miR-122, miR-142-3p, miR-192, miR-222, and miR-378a and downregulation of miR-138 and miR-221 (188-190). Among these, miR-222 is a negative regulator of insulin sensitivity in adipocytes, where it reduces GLUT4-mediated glucose uptake (191), and hepatocytes, where it targets IRS-1 (192). miR-222 levels increase in blood $(193,194)$ and fat (195) with obesity (193-195). Circulating miR-222 is both found in exosomes and associated with HDL (196, 197). Mice injected with exosomes containing miR-122 mimetics develop metabolic dysfunction with insulin resistance and dyslipidemia (190). Likewise, miR-155 released in exosomes from adipose tissue macrophages during inflammation has been shown to be transferred to adipocytes, myotubes, or hepatocytes, where it worsens insulin resistance (182).

Adipose-derived exosomal miRNAs may also serve paracrine functions. Thus, miRNA-containing vesicles released from large adipocytes can be transferred to small adipocytes and stimulate lipogenesis and adipocyte hypertrophy (198). Secretion of miRNAs by adipocytes may also be regulated by FFA and $\mathrm{H}_{2} \mathrm{O}_{2}$ (198), indicating that signals promoting lipid accumulation and insulin resistance may spread from insulin-resistant adipocytes to newly formed adipocytes. Conversely, amelioration of metabolic dysfunction by weight loss may be due in part to changes in circulating miRNAs (199). In addition, miRNAs differentially released in the circulation of obese versus lean subjects may act on the TGF- $\beta$ pathway, thus providing a link to nonalcoholic fatty liver disease $(200,201)$. This may be part of a more complex regulatory loop in which TGF- $\beta$ induces adipocyte secretion of miR- $130 \mathrm{~b}$, which is then transferred to muscle, where it acts to reduce the expression of PGC-1 $\alpha$, reducing muscle oxidative metabolism (202). Skeletal muscle is also responsive to miR-27a, which is present in adipose-derived exosomes and induces insulin resistance via PPAR $\gamma$ repression (203). Serum levels of miR-27a are positively associated with obesity and insulin resistance in children and in mice with obesity, indicating that miR-27a may be another modulator of obesity-associated insulin resistance (203).

Inflammation in adipose tissue and liver may also be mediated, in part, by circulating adipocyte-derived exosomes. Mice injected with extracellular vesicles from adipose tissue of obese mice develop increased levels of circulating IL- 6 and TNF- $\alpha$ and develop insulin resistance (204). This appears to be controlled by miR-155, which can target SOCS1 in macrophages, promote STAT1 signaling, and suppress STAT6 signaling, thereby promoting M1 macrophage polarization (205). Conversely, it has been shown that extracellular vesicles from adipose tissue macrophages of obese mice, which contain miR-155, can induce insulin resistance when administrated to lean mice or incubated in vitro with adipocytes, myocytes, or hepatocytes, and knockout of miR-155 in HFD-fed mice results in improved insulin sensitivity (182). This effect is reversed by transplantation of WT bone marrow, further supporting a role for exosomal miRNAs in adipocyte-macrophage crosstalk $(206,207)$. Exosomes secreted by adipose-derived stem cells may also contribute to effects on macrophages (208) and vascular integrity in obesity $(209,210)$. Together these data indicate that adipose tissue is a major contributor to circulating exosomal miRNAs and that adipose-derived exosomes may possess hormone-like functions, communicating with other tissues to coordinate metabolic homeostasis and energy balance. When these systems are perturbed, they may also contribute importantly to the pathophysiology of metabolic diseases.

\section{Targeting adipose tissue to treat metabolic syndrome}

From the evidence above, it is clear that targeting adipose tissue and its signaling molecules can provide unique opportunities to better understand the pathophysiology and treatment of obesity, insulin resistance, T2D, and metabolic syndrome. While considerable effort has already been made to target the inflammation in adipose tissue as a component of insulin resistance and some work has been devoted to finding AdipoR agonists, there remains great opportunity to find mimics or antagonists of other adipose hormones. This includes not only the peptide adipose hormones, but also bioactive signaling lipids secreted by white and brown fat. Adipose-secreted exosomal miRNAs might also provide new diagnostics to distinguish metabolically healthy versus metabolically unhealthy obesity and new approaches to deliver miRNAs that target genes in liver and other tissues to regulate metabolic syndrome. Finally, understand- 
ing the heterogeneity of adipose tissue - both from the perspective of white, brown, and beige fat and within WAT itself - offers a unique opportunity to develop drugs that can change distribution of adipose tissue as well as shift it from a metabolically unhealthy subtype to a more metabolically healthy subtype. With modern technologies, all of these opportunities are within the reach of reality.

\section{Acknowledgments}

This work was supported by NIH grant R01DK082659 and the Mary K. Iacocca Professorship to CRK, the American Diabetes
Association Junior Faculty Development Award (1-17-JDF-055) to KYL, and an American Diabetes Association-Pfizer postdoc fellowship (9-17-CMF-016) to GW. The authors also acknowledge the many investigators who have contributed to this area of research, and whose work, in many cases, could not be cited owing to limitation of references allowed in this Review.

Address correspondence to: C. Ronald Kahn, Joslin Diabetes Center, One Joslin Place, Boston, Massachusetts 02215, USA. Phone: 617.309.2635; Email: c.ronald.kahn@joslin.harvard.edu.
1. Cypess AM, Kahn CR. The role and importance of brown adipose tissue in energy homeostasis. Curr Opin Pediatr. 2010;22(4):478-484.

2. Nedergaard J, Bengtsson T, Cannon B. New powers of brown fat: fighting the metabolic syndrome. Cell Metab. 2011;13(3):238-240.

3. Garg A. Clinical review. Lipodystrophies: genetic and acquired body fat disorders. JClin Endocrinol Metab. 2011;96(11):3313-3325.

4. Smith U, Kahn BB. Adipose tissue regulates insulin sensitivity: role of adipogenesis, de novo lipogenesis and novel lipids. JIntern Med. 2016;280(5):465-475.

5. Kwon H, Pessin JE. Adipokines mediate inflammation and insulin resistance. Front Endocrinol (Lausanne). 2013;4:71.

6. Thomou T, et al. Adipose-derived circulating miRNAs regulate gene expression in other tissues. Nature. 2017;542(7642):450-455.

7. Branca RT, et al. Accurate quantification of brown adipose tissue mass by xenon-enhanced computed tomography. Proc Natl Acad Sci U S A. 2018;115(1):174-179.

8. Mao L, et al. Visualization and quantification of browning using a Ucp1-2A-luciferase knock-in mouse model. Diabetes. 2017;66(2):407-417.

9. Tang W, et al. White fat progenitor cells reside in the adipose vasculature. Science. 2008;322(5901):583-586.

10. Berry R, Rodeheffer MS. Characterization of the adipocyte cellular lineage in vivo. Nat Cell Biol. 2013;15(3):302-308.

11. Vishvanath L, et al. Pdgfr $\beta^{+}$mural preadipocytes contribute to adipocyte hyperplasia induced by high-fat-diet feeding and prolonged cold exposure in adult mice. Cell Metab. 2016;23(2):350-359.

12. Schwalie PC, et al. A stromal cell population that inhibits adipogenesis in mammalian fat depots. Nature. 2018;559(7712):103-108.

13. Zhang R, et al. FSP1-positive fibroblasts are adipogenic niche and regulate adipose homeostasis. PLoS Biol. 2018;16(8):e2001493.

14. Ghaben AL, Scherer PE. Adipogenesis and metabolic health. Nat Rev Mol Cell Biol. 2019;20(4):242-258.

15. Fox CS, et al. Abdominal visceral and subcutaneous adipose tissue compartments: association with metabolic risk factors in the Framingham Heart Study. Circulation. 2007;116(1):39-48.

16. McLaughlin T, Lamendola C, Liu A, Abbasi F. Preferential fat deposition in subcutaneous versus visceral depots is associated with insulin sensitivity. J Clin Endocrinol Metab. 2011;96(11):E1756-E1760.
17. Kumagai N, Morii N, Fujisawa K, Nemoto Y, Narumiya S. ADP-ribosylation of rho p21 inhibits lysophosphatidic acid-induced protein tyrosine phosphorylation and phosphatidylinositol 3-kinase activation in cultured Swiss 3T3 cells. J Biol Chem. 1993;268(33):24535-24538.

18. Tran TT, Yamamoto Y, Gesta S, Kahn CR. Beneficial effects of subcutaneous fat transplantation on metabolism. Cell Metab. 2008;7(5):410-420.

19. Stanford KI, et al. A novel role for subcutaneous adipose tissue in exercise-induced improvements in glucose homeostasis. Diabetes. 2015;64(6):2002-2014.

20. Macotela Y, et al. Intrinsic differences in adipocyte precursor cells from different white fat depots. Diabetes. 2012;61(7):1691-1699.

21. Tchkonia T, et al. Fat depot-specific characteristics are retained in strains derived from single human preadipocytes. Diabetes. 2006;55(9):2571-2578.

22. Lafontan M, Girard J. Impact of visceral adipose tissue on liver metabolism. Part I: heterogeneity of adipose tissue and functional properties of visceral adipose tissue. Diabetes Metab. 2008;34(4 pt 1):317-327.

23. Arner $\mathrm{P}$, Hellström L, Wahrenberg $\mathrm{H}$, Brönnegård M. Beta-adrenoceptor expression in human fat cells from different regions. JClin Invest. 1990;86(5):1595-1600.

24. Yamamoto Y, Gesta S, Lee KY, Tran TT, Saadatirad P, Kahn CR. Adipose depots possess unique developmental gene signatures. Obesity (Silver Spring). 2010;18(5):872-878.

25. Gesta S, et al. Evidence for a role of developmental genes in the origin of obesity and body fat distribution. Proc Natl Acad Sci U S A. 2006;103(17):6676-6681.

26. Lee KY, et al. Shox 2 is a molecular determinant of depot-specific adipocyte function. Proc Natl Acad Sci U S A. 2013;110(28):11409-11414.

27. Ussar S, Bezy O, Blüher M, Kahn CR. Glypican-4 enhances insulin signaling via interaction with the insulin receptor and serves as a novel adipokine. Diabetes. 2012;61(9):2289-2298.

28. Mori M, Nakagami H, Rodriguez-Araujo G, Nimura K, Kaneda Y. Essential role for miR-196a in brown adipogenesis of white fat progenitor cells. PLoS Biol. 2012;10(4):e1001314.

29. Cao W, Huang H, Xia T, Liu C, Muhammad S, Sun C. Homeobox a5 promotes white adipose tissue browning through inhibition of the tenascin C/toll-like receptor 4/nuclear factor kappa b inflammatory signaling in mice. Front Immunol. 2018;9:647.
30. Driskell RR, Jahoda CA, Chuong CM, Watt FM, Horsley V. Defining dermal adipose tissue. Exp Dermatol. 2014;23(9):629-631.

31. Plikus MV, et al. Regeneration of fat cells from myofibroblasts during wound healing. Science. 2017;355(6326):748-752.

32. Chen J, Shi Y, Regan J, Karuppaiah K, Ornitz DM, Long F. Osx-Cre targets multiple cell types besides osteoblast lineage in postnatal mice. PLoS One. 2014;9(1):e85161.

33. Craft CS, Li Z, MacDougald OA, Scheller EL. Molecular differences between subtypes of bone marrow adipocytes. Curr Mol Biol Rep. 2018;4(1):16-23.

34. Wang H, Leng Y, Gong Y. Bone marrow fat and hematopoiesis. Front Endocrinol (Lausanne). 2018;9:694.

35. Maridas DE, et al. Progenitor recruitment and adipogenic lipolysis contribute to the anabolic actions of parathyroid hormone on the skeleton. FASEB J. 2019;33(2):2885-2898.

36. Cordes $\mathrm{C}$, et al. MR-detected changes in liver fat, abdominal fat, and vertebral bone marrow fat after a four-week calorie restriction in obese women. J Magn Reson Imaging. 2015;42(5):1272-1280.

37. Cawthorn WP, et al. Bone marrow adipose tissue is an endocrine organ that contributes to increased circulating adiponectin during caloric restriction. Cell Metab. 2014;20(2):368-375.

38. Varlamov O, Chu M, Cornea A, Sampath H, Roberts CT. Cell-autonomous heterogeneity of nutrient uptake in white adipose tissue of rhesus macaques. Endocrinology. 2015;156(1):80-89.

39. Katz LS, Geras-Raaka E, Gershengorn MC. Heritability of fat accumulation in white adipocytes. Am J Physiol Endocrinol Metab. 2014;307(3):E335-E344.

40. Lee KY, et al. Tbx15 defines a glycolytic subpopulation and white adipocyte heterogeneity. Diabetes. 2017;66(11):2822-2829.

41. Hagberg CE, et al. Flow cytometry of mouse and human adipocytes for the analysis of browning and cellular heterogeneity. Cell Rep. 2018;24(10):2746-2756.e5.

42. Blüher M, Patti ME, Gesta S, Kahn BB, Kahn CR. Intrinsic heterogeneity in adipose tissue of fatspecific insulin receptor knock-out mice is associated with differences in patterns of gene expression. J Biol Chem. 2004;279(30):31891-31901.

43. Wang SP, et al. The adipose tissue phenotype of hormone-sensitive lipase deficiency in mice. Obes Res. 2001;9(2):119-128.

44. Marcelin G, et al. A PDGFR $\alpha$-mediated switch toward CD $9^{\text {high }}$ adipocyte progenitors controls 
obesity-induced adipose tissue fibrosis. Cell Metab. 2017;25(3):673-685.

45. Lee KY, Luong Q, Sharma R, Dreyfuss JM, Ussar S, Kahn CR. Developmental and functional heterogeneity of white adipocytes within a single fat depot. EMBO J. 2019;38(3):e99291.

46. Min SY, et al. Multiple human adipocyte subtypes and mechanisms of their development. bioRxiv. https://www.biorxiv.org/content/ 10.1101/537464v1. Published January 31, 2019. Accessed August 15, 2019.

47. Jiang Y, Berry DC, Tang W, Graff JM. Independent stem cell lineages regulate adipose organogenesis and adipose homeostasis. Cell Rep. 2014;9(3):1007-1022.

48. Klein D, Weisshardt P, Kleff V, Jastrow H, Jakob $\mathrm{HG}$, Ergün S. Vascular wall-resident CD $44^{+}$ multipotent stem cells give rise to pericytes and smooth muscle cells and contribute to new vessel maturation. PLoS One. 2011;6(5):e20540.

49. Gupta RK, et al. Zfp423 expression identifies committed preadipocytes and localizes to adipose endothelial and perivascular cells. Cell Metab. 2012;15(2):230-239.

50 . Topley N, et al. Human peritoneal mesothelial cells synthesize interleukin-8. Synergistic induction by interleukin-1 beta and tumor necrosis factor-alpha. Am J Pathol. 1993;142(6):1876-1886.

51. Darimont C, et al. Contribution of mesothelial cells in the expression of inflammatory-related factors in omental adipose tissue of obese subjects. Int JObes (Lond). 2008;32(1):112-120.

52. Sanchez-Gurmaches J, Guertin DA. Adipocyte lineages: tracing back the origins of fat. Biochim Biophys Acta. 2014;1842(3):340-351.

53. Sebo ZL, Jeffery E, Holtrup B, Rodeheffer MS. A mesodermal fate map for adipose tissue. Development. 2018;145(17):dev166801.

54. Krueger KC, Costa MJ, Du H, Feldman BJ. Characterization of Cre recombinase activity for in vivo targeting of adipocyte precursor cells. Stem Cell Reports. 2014;3(6):1147-1158.

55. Sanchez-Gurmaches J, Hsiao WY, Guertin DA. Highly selective in vivo labeling of subcutaneous white adipocyte precursors with Prx1-Cre. Stem Cell Reports. 2015;4(4):541-550.

56. Tomiyama K, et al. Characterization of transplanted $\mathrm{GFP}^{+}$bone marrow cells into adipose tissue. Stem Cells. 2008;26(2):330-338.

57. Billon $\mathrm{N}$, et al. The generation of adipocytes by the neural crest. Development. 2007;134(12):2283-2292.

58. Matsuoka T, et al. Neural crest origins of the neck and shoulder. Nature. 2005;436(7049):347-355.

59. Sowa Y, et al. Adipose stromal cells contain phenotypically distinct adipogenic progenitors derived from neural crest. PLoS One. 2013;8(12):e84206.

60. Xue R, et al. Clonal analyses and gene profiling identify genetic biomarkers of the thermogenic potential of human brown and white preadipocytes. Nat Med. 2015;21(7):760-768.

61. Lidell ME, et al. Evidence for two types of brown adipose tissue in humans. Nat Med. 2013;19(5):631-634.

62. Shinoda K, et al. Genetic and functional characterization of clonally derived adult human brown adipocytes. Nat Med. 2015;21(4):389-394.
63. Lee YH, Kim SN, Kwon HJ, Granneman JG. Metabolic heterogeneity of activated beige/brite adipocytes in inguinal adipose tissue. Sci Rep. 2017;7:39794

64. Long JZ, et al. A smooth muscle-like origin for beige adipocytes. Cell Metab. 2014;19(5):810-820

65. Chen Y, et al. Thermal stress induces glycolytic beige fat formation via a myogenic state. Nature. 2019;565(7738):180-185.

66. Mann JP, Savage DB. What lipodystrophies teach us about the metabolic syndrome. JClin Invest. 2019;129(10):4009-4021.

67. Brown RJ, et al. The diagnosis and management of lipodystrophy syndromes: a multi-society practice guideline. JClin Endocrinol Metab. 2016;101(12):4500-4511.

68. Erion DM, Shulman GI. Diacylglycerol-mediated insulin resistance. Nat Med. 2010;16(4):400-402.

69. Wong VW, et al. Fatty pancreas, insulin resistance, and $\beta$-cell function: a population study using fat-water magnetic resonance imaging. Am J Gastroenterol. 2014;109(4):589-597.

70. Winzell MS, et al. Pancreatic $\beta$-cell lipotoxicity induced by overexpression of hormone-sensitive lipase. Diabetes. 2003;52(8):2057-2065.

71. Khan T, et al. Metabolic dysregulation and adipose tissue fibrosis: role of collagen VI. Mol Cell Biol. 2009;29(6):1575-1591.

72. Kusminski CM, et al. MitoNEET-driven alterations in adipocyte mitochondrial activity reveal a crucial adaptive process that preserves insulin sensitivity in obesity. Nat Med. 2012;18(10):1539-1549.

73. Schweiger M, et al. Pharmacological inhibition of adipose triglyceride lipase corrects high-fat diet-induced insulin resistance and hepatosteatosis in mice. Nat Commun. 2017;8:14859.

74. Brown RJ, et al. Metreleptin-mediated improvements in insulin sensitivity are independent of food intake in humans with lipodystrophy. J Clin Invest. 2018;128(8):3504-3516.

75. Shimomura I, Hammer RE, Ikemoto S, Brown MS, Goldstein JL. Leptin reverses insulin resistance and diabetes mellitus in mice with congenital lipodystrophy. Nature. 1999;401(6748):73-76

76. Haque WA, Oral EA, Dietz K, Bowcock AM, Agarwal AK, Garg A. Risk factors for diabetes in familial partial lipodystrophy, Dunnigan variety. Diabetes Care. 2003;26(5):1350-1355.

77. Köbberling J, Dunnigan MG. Familial partial lipodystrophy: two types of an X linked dominan syndrome, lethal in the hemizygous state. JMed Genet. 1986;23(2):120-127.

78. Chudasama KK, et al. SHORT syndrome with partial lipodystrophy due to impaired phosphatidylinositol 3 kinase signaling. Am J Hum Genet. 2013;93(1):150-157.

79. Small JE, et al. Barraquer-Simons Syndrome. Am JMed Sci. 2016;352(3):280-284.

80. Agarwal AK, Garg A. Genetic disorders of adipose tissue development, differentiation, and death. Annu Rev Genomics Hum Genet. 2006;7:175-199.

81. George S, et al. A family with severe insulin resistance and diabetes due to a mutation in AKT2. Science. 2004;304(5675):1325-1328.

82. Rubio-Cabezas O, et al. Partial lipodystrophy and insulin resistant diabetes in a patient with a homozygous nonsense mutation in CIDEC.
EMBO Mol Med. 2009;1(5):280-287.

83. Mori MA, et al. Altered miRNA processing disrupts brown/white adipocyte determination and associates with lipodystrophy. JClin Invest. 2014;124(8):3339-3351.

84. Torriani M, et al. Dysfunctional subcutaneous fat with reduced dicer and brown adipose tissue gene expression in HIV-infected patients. JClin Endocrinol Metab. 2016;101(3):1225-1234.

85. Hirsch J, Batchelor B. Adipose tissue cellularity in human obesity. Clin Endocrinol Metab. 1976;5(2):299-311.

86. Spalding KL, et al. Dynamics of fat cell turnover in humans. Nature. 2008;453(7196):783-787.

87. Tchoukalova YD, Votruba SB, Tchkonia T, Giorgadze N, Kirkland JL, Jensen MD. Regional differences in cellular mechanisms of adipose tissue gain with overfeeding. Proc Natl Acad Sci U S A. 2010;107(42):18226-18231.

88. Arner E, et al. Adipocyte turnover: relevance to human adipose tissue morphology. Diabetes. 2010;59(1):105-109.

89. Neese RA, et al. Measurement in vivo of proliferation rates of slow turnover cells by $2 \mathrm{H}_{2} \mathrm{O}$ labeling of the deoxyribose moiety of DNA. Proc Natl Acad Sci U S A. 2002;99(24):15345-15350.

90. Steinhauser ML, et al. Multi-isotope imaging mass spectrometry quantifies stem cell division and metabolism. Nature. 2012;481(7382):516-519.

91. Strissel KJ, et al. Adipocyte death, adipose tissue remodeling, and obesity complications. Diabetes. 2007;56(12):2910-2918.

92. Jeffery E, Church CD, Holtrup B, Colman L, Rodeheffer MS. Rapid depot-specific activation of adipocyte precursor cells at the onset of obesity. Nat Cell Biol. 2015;17(4):376-385.

93. Wang QA, Tao C, Gupta RK, Scherer PE. Tracking adipogenesis during white adipose tissue development, expansion and regeneration. Nat Med. 2013;19(10):1338-1344.

94. Pajvani UB, et al. Fat apoptosis through targeted activation of caspase 8: a new mouse model of inducible and reversible lipoatrophy. Nat Med. 2005;11(7):797-803.

95. Sakaguchi M, et al. Adipocyte dynamics and reversible metabolic syndrome in mice with an inducible adipocyte-specific deletion of the insulin receptor. Cell Metab. 2017;25(2):448-462.

96. De Matteis R, et al. In vivo physiological transdifferentiation of adult adipose cells. Stem Cells. 2009;27(11):2761-2768.

97. Poloni A, et al. Human dedifferentiated adipocytes show similar properties to bone marrow-derived mesenchymal stem cells. Stem Cells. 2012;30(5):965-974.

98. Morroni M, et al. Reversible transdifferentiation of secretory epithelial cells into adipocytes in the mammary gland. Proc Natl Acad Sci US A. 2004;101(48):16801-16806.

99. Joshi PA, et al. PDGFR $\alpha^{+}$stromal adipocyte progenitors transition into epithelial cells during lobulo-alveologenesis in the murine mammary gland. Nat Commun. 2019;10(1):1760

100. Bochet L, et al. Adipocyte-derived fibroblasts promote tumor progression and contribute to the desmoplastic reaction in breast cancer. Cancer Res. 2013;73(18):5657-5668.

101.Jumabay M, et al. Dedifferentiated fat cells 
convert to cardiomyocyte phenotype and repair infarcted cardiac tissue in rats. J Mol Cell Cardiol. 2009;47(5):565-575.

102. Liao Y, Zeng Z, Lu F, Dong Z, Chang Q, Gao J. In vivo dedifferentiation of adult adipose cells. PLOS One. 2015;10(4):e0125254.

103. Friedman JM. Leptin at $14 \mathrm{y}$ of age: an ongoing story. Am J Clin Nutr. 2009;89(3):973S-979S.

104. Münzberg H, Morrison CD. Structure, production and signaling of leptin. Metab Clin Exp. 2015;64(1):13-23.

105. Myers MG, Cowley MA, Münzberg H. Mechanisms of leptin action and leptin resistance. Annu Rev Physiol. 2008;70:537-556.

106.Friedman JM. The function of leptin in nutrition, weight, and physiology. Nutr Rev. 2002;60(10 pt 2):S1-S14.

107. Tartaglia LA, et al. Identification and expression cloning of a leptin receptor, OB-R. Cell. 1995;83(7):1263-1271.

108. Farooqi IS, O'Rahilly S. 20 years of leptin: human disorders of leptin action. JEndocrinol. 2014;223(1):T63-T70.

109. Flier JS. Hormone resistance in diabetes and obesity: insulin, leptin, and FGF21. Yale J Biol Med. 2012;85(3):405-414.

110. Ahima RS, et al. Role of leptin in the neuroendocrine response to fasting. Nature. 1996;382(6588):250-252.

111. Flier JS, Maratos-Flier E. Leptin's physiologic role: does the emperor of energy balance have no clothes? Cell Metab. 2017;26(1):24-26.

112. Chan JL, Mantzoros CS. Leptin and the hypothalamic-pituitary regulation of the gonadotropin-gonadal axis. Pituitary. 2001;4(1-2):87-92.

113. Nagatani S, Guthikonda P, Thompson RC, Tsukamura H, Maeda KI, Foster DL. Evidence for GnRH regulation by leptin: leptin administration prevents reduced pulsatile LH secretion during fasting. Neuroendocrinology. 1998;67(6):370-376.

114. Wang MY, et al. Leptin therapy in insulindeficient type I diabetes. Proc Natl Acad Sci U S A. 2010;107(11):4813-4819.

115. Shetty S, Kusminski CM, Scherer PE. Adiponectin in health and disease: evaluation of adiponectin-targeted drug development strategies. Trends Pharmacol Sci. 2009;30(5):234-239.

116. Kadowaki T, Yamauchi T, Kubota N, Hara K, Ueki $\mathrm{K}$, Tobe $\mathrm{K}$. Adiponectin and adiponectin receptors in insulin resistance, diabetes, and the metabolic syndrome. JClin Invest. 2006;116(7):1784-1792.

117. Goto M, et al. Low-molecular-weight adiponectin and high-molecular-weight adiponectin levels in relation to diabetes. Obesity (Silver Spring). 2014;22(2):401-407.

118. Semple RK, et al. Plasma adiponectin as a marker of insulin receptor dysfunction: clinical utility in severe insulin resistance. Diabetes Care. 2008;31(5):977-979.

119. Okada-Iwabu M, Iwabu M, Yamauchi T, Kadowaki T. Structure and function analysis of adiponectin receptors toward development of novel antidiabetic agents promoting healthy longevity. Endocr J. 2018;65(10):971-977.

120. Turer AT, Scherer PE. Adiponectin: mechanistic insights and clinical implications. Diabetologia. 2012;55(9):2319-2326.

121. Yamauchi $\mathrm{T}$, et al. Adiponectin stimulates glucose utilization and fatty-acid oxidation by activating AMP-activated protein kinase. Nat Med. 2002;8(11):1288-1295.

122. Holland WL, et al. Receptor-mediated activation of ceramidase activity initiates the pleiotropic actions of adiponectin. Nat Med. 2011;17(1):55-63.

123. Ahima RS, Lazar MA. Adipokines and the peripheral and neural control of energy balance. Mol Endocrinol. 2008;22(5):1023-1031.

124. Bloemer J, et al. Role of adiponectin in central nervous system disorders. Neural Plast. 2018;2018:4593530.

125. Spranger J, et al. Adiponectin does not cross the blood-brain barrier but modifies cytokine expression of brain endothelial cells. Diabetes. 2006;55(1):141-147.

126.Vaiopoulos AG, Marinou K, Christodoulides C, Koutsilieris M. The role of adiponectin in human vascular physiology. Int J Cardiol. 2012;155(2):188-193.

127. Steppan CM, Wang J, Whiteman EL, Birnbaum MJ, Lazar MA. Activation of SOCS-3 by resistin. Mol Cell Biol. 2005;25(4):1569-1575.

128. Hivert MF, et al. Associations of adiponectin, resistin, and tumor necrosis factor- $\alpha$ with insulin resistance. J Clin Endocrinol Metab. 2008;93(8):3165-3172.

129.Park HK, Kwak MK, Kim HJ, Ahima RS. Linking resistin, inflammation, and cardiometabolic diseases. Korean Jintern Med. 2017;32(2):239-247.

130. Yang $Q$, et al. Serum retinol binding protein 4 contributes to insulin resistance in obesity and type 2 diabetes. Nature. 2005;436(7049):356-362.

131. Thompson SJ, et al. Hepatocytes are the principal source of circulating RBP4 in mice. Diabetes. 2017;66(1):58-63.

132. Lee SA, Yuen JJ, Jiang H, Kahn BB, Blaner WS. Adipocyte-specific overexpression of retinol-binding protein 4 causes hepatic steatosis in mice. Hepatology. 2016;64(5):1534-1546.

133. Fasshauer M, Blüher M. Adipokines in health and disease. Trends Pharmacol Sci. 2015;36(7):461-470.

134. Boucher J, et al. Apelin, a newly identified adipokine up-regulated by insulin and obesity. Endocrinology. 2005;146(4):1764-1771.

135. Balli U, Bozkurt Dogan S, Ongoz Dede F, Sertoglu E, Keles GC. The levels of visceral adipose tissue-derived serpin, omentin-1 and tumor necrosis factor- $\alpha$ in the gingival crevicular fluid of obese patients following periodontal therapy. JOral Sci. 2016;58(4):465-473.

136. Ravussin A, et al. Loss of nucleobindin-2 causes insulin resistance in obesity without impacting satiety or adiposity. Cell Rep. 2018;24(5):1085-1092.e6

137. Bouchard L, et al. Comprehensive genetic analysis of the dipeptidyl peptidase- 4 gene and cardiovascular disease risk factors in obese individuals. Acta Diabetol. 2009;46(1):13-21.

138. Li X, et al. Plasma asprosin levels are associated with glucose metabolism, lipid, and sex hormone profiles in females with metabolic-related diseases. Mediators Inflamm. 2018;2018:7375294.

139. Tang QQ, Otto TC, Lane MD. Commitment of C3H10T1/2 pluripotent stem cells to the adipocyte lineage. Proc Natl Acad Sci U S A. 2004;101(26):9607-9611.

140. Huang $\mathrm{H}$, et al. BMP signaling pathway is required for commitment of C3H10T1/2 pluripotent stem cells to the adipocyte lineage. Proc Natl Acad Sci U S A. 2009;106(31):12670-12675.

141. Schulz TJ, et al. Identification of inducible brown adipocyte progenitors residing in skeletal muscle and white fat. Proc Natl Acad Sci U S A. 2011;108(1):143-148.

142. Whittle AJ, et al. BMP8B increases brown adipose tissue thermogenesis through both central and peripheral actions. Cell. 2012;149(4):871-885.

143. Bagchi M, Kim LA, Boucher J, Walshe TE, Kahn CR, D'Amore PA. Vascular endothelial growth factor is important for brown adipose tissue development and maintenance. FASEB J. 2013;27(8):3257-3271.

144.Ye J. Emerging role of adipose tissue hypoxia in obesity and insulin resistance. Int JObes (Lond). 2009;33(1):54-66.

145. Corvera S, Gealekman O. Adipose tissue angiogenesis: impact on obesity and type-2 diabetes. Biochim Biophys Acta. 2014;1842(3):463-472.

146.Williamson RT. On the treatment of glycosuria and diabetes mellitus with sodium salicylate. $\mathrm{Br}$ Med J. 1901;1(2100):760-762.

147. Kopp E, Ghosh S. Inhibition of NF- $\kappa$ B by sodium salicylate and aspirin. Science. 1994;265(5174):956-959.

148. Yuan M, et al. Reversal of obesity- and dietinduced insulin resistance with salicylates or targeted disruption of Ikkbeta. Science. 2001;293(5535):1673-1677.

149. Donath MY, Shoelson SE. Type 2 diabetes as an inflammatory disease. Nat Rev Immunol. 2011;11(2):98-107.

150. Hotamisligil GS, Shargill NS, Spiegelman BM. Adipose expression of tumor necrosis factor- $\alpha$ : direct role in obesity-linked insulin resistance. Science. 1993;259(5091):87-91.

151. Feinstein R, Kanety H, Papa MZ, Lunenfeld B, Karasik A. Tumor necrosis factor- $\alpha$ suppresses insulin-induced tyrosine phosphorylation of insulin receptor and its substrates. J Biol Chem. 1993;268(35):26055-26058.

152. Stanley TL, et al. TNF- $\alpha$ antagonism with etanercept decreases glucose and increases the proportion of high molecular weight adiponectin in obese subjects with features of the metabolic syndrome. J Clin Endocrinol Metab. 2011;96(1):E146-E150.

153. Wascher TC, Lindeman JH, Sourij H, Kooistra T, Pacini G, Roden M. Chronic TNF- $\alpha$ neutralization does not improve insulin resistance or endothelial function in "healthy" men with metabolic syndrome. Mol Med. 2011;17(3-4):189-193.

154. Paquot N, Castillo MJ, Lefèbvre PJ, Scheen AJ. No increased insulin sensitivity after a single intravenous administration of a recombinant human tumor necrosis factor receptor: $\mathrm{Fc}$ fusion protein in obese insulin-resistant patients. J Clin Endocrinol Metab. 2000;85(3):1316-1319.

155. Shimobayashi M, et al. Insulin resistance causes inflammation in adipose tissue. JClin Invest. 2018;128(4):1538-1550.

156. Lee YS, et al. Inflammation is necessary for longterm but not short-term high-fat diet-induced insulin resistance. Diabetes. 2011;60(10):2474-2483.

157. Wernstedt Asterholm I, et al. Adipocyte inflammation is essential for healthy adipose 
tissue expansion and remodeling. Cell Metab. 2014;20(1):103-118.

158. Lumeng CN, Bodzin JL, Saltiel AR. Obesity induces a phenotypic switch in adipose tissue macrophage polarization. JClin Invest. 2007;117(1):175-184.

159. Wu H, et al. T-cell accumulation and regulated on activation, normal $\mathrm{T}$ cell expressed and secreted upregulation in adipose tissue in obesity. Circulation. 2007;115(8):1029-1038.

160. Nishimura S, et al. CD8 ${ }^{+}$effector T cells contribute to macrophage recruitment and adipose tissue inflammation in obesity. Nat Med. 2009;15(8):914-920.

161. Kang YS, et al. CCR2 antagonism improves insulin resistance, lipid metabolism, and diabetic nephropathy in type 2 diabetic mice. Kidney Int 2010;78(9):883-894.

162. Reilly M, et al. Randomized, double-blind, placebo-controlled, dose-escalating phase I, healthy subjects study of intravenous OPN-305, a humanized anti-TLR2 antibody. Clin Pharmacol Ther. 2013;94(5):593-600.

163. Oral EA, et al. Inhibition of IKK $\varepsilon$ and TBK1 improves glucose control in a subset of patients with type 2 diabetes. Cell Metab. 2017;26(1):157-170.e7.

164. Marcelin G, Silveira ALM, Martins LB, Ferreira AVM, Clément K. Deciphering the cellular interplays underlying obesity-induced adipose tissue fibrosis. J Clin Invest. 2019;129(10):4032-4040.

165. Lackey DE, et al. Contributions of adipose tissue architectural and tensile properties toward defining healthy and unhealthy obesity. Am JPhysiol Endocrinol Metab. 2014;306(3):E233-E246.

166. Hasegawa $Y$, et al. Repression of adipose tissue fibrosis through a PRDM16-GTF2IRD1 complex improves systemic glucose homeostasis. Cell Metab. 2018;27(1):180-194.e6.

167. Yore MM, et al. Discovery of a class of endogenous mammalian lipids with anti-diabetic and antiinflammatory effects. Cell. 2014;159(2):318-332.

168. Syed I, et al. Palmitic acid hydroxystearic acids activate GPR40, which is involved in their beneficial effects on glucose homeostasis. Cell Metab. 2018;27(2):419-427.e4.

169. Kuda O. Bioactive metabolites of docosahexaenoic acid. Biochimie. 2017;136:12-20.

170.Kolar MJ, et al. Branched fatty acid esters of hydroxy fatty acids are preferred substrates of the MODY8 protein carboxyl ester lipase. Biochemistry. 2016;55(33):4636-4641.

171. Parsons WH, et al. AIG1 and ADTRP are atypical integral membrane hydrolases that degrade bioactive FAHFAs. Nat Chem Biol. 2016;12(5):367-372.

172. Lynes MD, et al. The cold-induced lipokine 12,13-diHOME promotes fatty acid transport into brown adipose tissue. Nat Med. 2017;23(5):631-637.

173. Stanford KI, et al. 12,13-diHOME: an exerciseinduced lipokine that increases skeletal muscle fatty acid uptake. Cell Metab. 2018;27(5):1111-1120.e3.

174. Zimmer B, et al. The oxidized linoleic acid metabolite 12,13-DiHOME mediates thermal hyperalgesia during inflammatory pain. Biochim Biophys Acta Mol Cell Biol Lipids. 2018;1863(7):669-678.

175. Ludwig N, et al. Distribution of miRNA expres- sion across human tissues. Nucleic Acids Res. 2016;44(8):3865-3877.

176. Herrera BM, et al. MicroRNA-125a is overexpressed in insulin target tissues in a spontaneous rat model of Type 2 Diabetes. BMC Med Genomics. 2009;2:54.

177. Sun L, et al. Mir193b-365 is essential for brown fat differentiation. Nat Cell Biol. 2011;13(8):958-965.

178. Ortega FJ, et al. MiRNA expression profile of human subcutaneous adipose and during adipocyte differentiation. PLoS One. 2010;5(2):e9022.

179. Arner P, Kulyté A. MicroRNA regulatory networks in human adipose tissue and obesity. Nat Rev Endocrinol. 2015;11(5):276-288.

180. Kim HJ, et al. MicroRNAs are required for the feature maintenance and differentiation of brown adipocytes. Diabetes. 2014;63(12):4045-4056.

181. Reis FC, et al. Fat-specific Dicer deficiency accelerates aging and mitigates several effects of dietary restriction in mice. Aging (Albany NY). 2016;8(6):1201-1222.

182. Ying $\mathrm{W}$, et al. Adipose tissue macrophagederived exosomal miRNAs can modulate in vivo and in vitro insulin sensitivity. Cell. 2017;171(2):372-384.e12.

183. Higuchi C, et al. Identification of circulating miR101, miR-375 and miR-802 as biomarkers for type 2 diabetes. Metab Clin Exp. 2015;64(4):489-497.

184. Kong L, et al. Significance of serum microRNAs in pre-diabetes and newly diagnosed type 2 diabetes: a clinical study. Acta Diabetol. 2011;48(1):61-69.

185. Sun K, et al. Expression and DNA methylation status of microRNA-375 in patients with type 2 diabetes mellitus. Mol Med Rep. 2014;9(3):967-972.

186.Latreille M, et al. miR-375 gene dosage in pancreatic $\beta$-cells: implications for regulation of $\beta$-cell mass and biomarker development. J Mol Med. 2015;93(10):1159-1169.

187. Karolina DS, et al. Circulating miRNA profiles in patients with metabolic syndrome. JClin Endocrinol Metab. 2012;97(12):E2271-E2276.

188. Can U, Buyukinan M, Yerlikaya FH. The investigation of circulating microRNAs associated with lipid metabolism in childhood obesity. Pediatr Obes. 2016;11(3):228-234.

189. Willeit P, et al. Circulating MicroRNA-122 is associated with the risk of new-onset metabolic syndrome and type 2 diabetes. Diabetes. 2017;66(2):347-357.

190.Castaño C, Kalko S, Novials A, Párrizas M. Obesity-associated exosomal miRNAs modulate glucose and lipid metabolism in mice. Proc Natl Acad Sci U S A. 2018;115(48):12158-12163.

191. Shi Z, et al. Differential expression of microRNAs in omental adipose tissue from gestational diabetes mellitus subjects reveals miR-222 as a regulator of ER $\alpha$ expression in estrogen-induced insulin resistance. Endocrinology. 2014;155(5):1982-1990.

192. Ono K, et al. Identification of microRNA that represses IRS-1 expression in liver. PLoS One. 2018;13(1):e0191553.

193. Ortega FJ, et al. Profiling of circulating microRNAs reveals common microRNAs linked to type 2 diabetes that change with insulin sensitization. Diabetes Care. 2014;37(5):1375-1383.

194. Villard A, Marchand L, Thivolet C, Rome S. Diagnostic value of cell-free circulating microRNAs for obesity and type 2 diabetes: a meta-analysis. JMol Biomark Diagn. 2015;6(6):251.

195. Chartoumpekis DV, et al. Differential expression of microRNAs in adipose tissue after long-term high-fat diet-induced obesity in mice. PLoS One. 2012;7(4):e34872.

196. Santangelo A, et al. A microRNA signature from serum exosomes of patients with glioma as complementary diagnostic biomarker. J Neurooncol. 2018;136(1):51-62.

197. Vickers KC, Palmisano BT, Shoucri BM, Shamburek RD, Remaley AT. MicroRNAs are transported in plasma and delivered to recipient cells by high-density lipoproteins. Nat Cell Biol. 2011;13(4):423-433.

198. Müller G, Schneider M, Biemer-Daub G, Wied S. Microvesicles released from rat adipocytes and harboring glycosylphosphatidylinositolanchored proteins transfer RNA stimulating lipid synthesis. Cell Signal. 2011;23(7):1207-1223.

199. Hubal MJ, et al. Circulating adipocyte-derived exosomal MicroRNAs associated with decreased insulin resistance after gastric bypass. Obesity (Silver Spring). 2017;25(1):102-110.

200.Ferrante SC, et al. Adipocyte-derived exosomal miRNAs: a novel mechanism for obesity-related disease. Pediatr Res. 2015;77(3):447-454.

201. Liu W, Baker RD, Bhatia T, Zhu L, Baker SS. Pathogenesis of nonalcoholic steatohepatitis. Cell Mol Life Sci. 2016;73(10):1969-1987.

202.Wang YC, et al. Circulating miR-130b mediates metabolic crosstalk between fat and muscle in overweight/obesity. Diabetologia. 2013;56(10):2275-2285.

203.Yu S, et al. Simultaneous knockout of CXCR4 and CCR5 genes in $\mathrm{CD} 4^{+} \mathrm{T}$ cells via CRISPR/ Cas9 confers resistance to both X4- and R5-tropic human immunodeficiency virus type 1 infection. Hum Gene Ther. 2018;29(1):51-67.

204.Deng ZB, et al. Adipose tissue exosome-like vesicles mediate activation of macrophage-induced insulin resistance. Diabetes. 2009;58(11):2498-2505.

205.Zhang Y, Mei H, Chang X, Chen F, Zhu Y, Han X. Adipocyte-derived microvesicles from obese mice induce M1 macrophage phenotype through secreted miR-155. JMol Cell Biol. 2016;8(6):505-517.

206.Lin X, et al. MiR-155 enhances insulin sensitivity by coordinated regulation of multiple genes in mice. PLoS Genet. 2016;12(10):e1006308.

207.De Silva N, Samblas M, Martínez JA, Milagro FI. Effects of exosomes from LPS-activated macrophages on adipocyte gene expression, differentiation, and insulin-dependent glucose uptake. JPhysiol Biochem. 2018;74(4):559-568.

208.Zhao H, et al. Exosomes from adipose-derived stem cells attenuate adipose inflammation and obesity through polarizing M2 macrophages and beiging in white adipose tissue. Diabetes. 2018;67(2):235-247.

209.Fish JE, et al. miR-126 regulates angiogenic signaling and vascular integrity. Dev Cell. 2008;15(2):272-284.

210. Togliatto G, et al. Obesity reduces the pro-angiogenic potential of adipose tissue stem cellderived extracellular vesicles (EVs) by impairing miR-126 content: impact on clinical applications. Int JObes (Lond). 2016;40(1):102-111. 